\title{
Assessment of strategies to build a welcoming STEM classroom environment for all students
}

\author{
C. De Grandi ${ }^{1,2}$, R. Ramos ${ }^{1}$, and S. G. J. Mochrie ${ }^{1,3}$ \\ ${ }^{1}$ Department of Physics, Yale University, New Haven, Connecticut 06520 \\ ${ }^{2}$ Department of Physics and Astronomy, University of Utah, Salt Lake City, Utah 84112 \\ ${ }^{3}$ Department of Applied Physics, Yale University, New Haven, Connecticut 06520
}

\begin{abstract}
We have designed, implemented and assessed a series of pedagogical strategies that seek to improve the climate of large introductory STEM courses and promote accessibility to students from all groups and backgrounds. These strategies rely on deliberately fostering collaboration among students, rather than competition, and promoting a culture that rewards effort and personal growth. We have collected and analyzed students' responses to our approach in a large introductory physics course over several semesters. We report that our strategies are successful in building a course community, in which students, regardless of demographic, perceive a welcoming atmosphere and feel supported and cared for by their classmates and instructors.
\end{abstract}

\section{INTRODUCTION}

National statistics $[1,2]$ clearly show that race and gender are key determinants of who is likely to pursue a career in science, technology, engineering, or mathematics (STEM) in the United States. Black, Hispanic, and American Indian/Alaskan Native students are significantly underrepresented in STEM disciplines, compared to their representation in the population as a whole, while White and Asian students are correspondingly overrepresented. In addition, despite a national effort to increase the number of women in STEM, only 30 percent of all STEM faculty are female [3].

Seymour and Hewitt [4] have investigated the causes for these race and gender disparities. They found that crucial factors that distinguish STEM from other fields include: its competitive culture, unsupportive classroom environments, and introductory classes that serve to "weed out" all but the highest achieving students. These aspects of STEM education have been shown to have a particularly detrimental impact on retention and success of female students [5] with further research suggesting that women experience STEM classroom environments as more competitive than their male classmates [6]. Women of color, in particular, are discouraged by the unwelcoming environment of large STEM classes and can find it challenging to persist in STEM majors for lack of support [7].

Another key finding is that a major contributing factor towards a student's success in STEM at college is the quality of that student's high-school education [8]. Therefore, because of the correlation across the US between the economic circumstances of a locality, the quality of its public schools, and its demographics, it is is not surprising that a greater proportion of under-represented minority (URM) students - who disproportionately come from economically disadvantaged localities - arrive in college academically less well-prepared in STEM subjects than their White and Asian classmates. Further- more, it has also been discovered [9] that the STEM underrepresentation of Black, Hispanic, and American Indian/Alaskan Native students at the bachelor's level, compared to White and Asian students, is not due to differences in these groups' college matriculation rates, but instead is the result of different graduation rates. Such studies highlight that the key challenge for STEM educators is not so much to increase the recruitment of URM students into STEM disciplines, but rather it is to improve URM retention. Studies show that teaching style can fundamentally affect the learning experience of students in science classes [10] and, in particular, that teaching style influences the retention of URM students [11]. In addition, student trust of the instructors - feeling supported and cared for by them - has been shown to be significantly related to class commitment and engagement, as well as final course grade [12]. Therefore, to improve the accessibility and inclusivity of the introductory physics course for life science majors, that we teach at a major research university in the United States, we recently implemented a series of pedagogical interventions designed to improve classroom climate, eliminate competition, and thus increase students' engagement and learning. Our strategies are described in detail in Ref. [13].

The purpose of this paper is to present an assessment of how successful these interventions are. To this end, we first summarize these interventions. Next, we describe the demographics of the class. Then, we present an analysis of students' responses to anonymous survey questions about the class, including a careful comparison between how URM and non-URM students perceive the class, how female and male students perceive the class, and how URM female students and non-URM male students perceive the class. Supporting our teaching approach, all students view the class climate positively. In addition, it is especially encouraging that the different groups of students examined - women, men, URMs, nonURMs, women of color, white men - all share similar responses to the class. 
TABLE I: Demographic of students for three consecutive semesters of introductory physics. Percentages may not sum to $100 \%$ for two reasons: i) Because of limited statistical significance, we chose not to include in our analysis students that identify as transgender, non-binary or preferred not to give their gender identity (overall 5-10\%); ii) 5-8\% of students preferred not to share their racial identities.

\begin{tabular}{l|r|r|r|r|r|r|r}
\hline \hline Course & Total & Women & Men & URM & non-URM & URM Women & non-URM Men \\
\hline Fall 2016 & 62 & $36(58 \%)$ & $20(32 \%)$ & $22(35 \%)$ & $37(60 \%)$ & $13(21 \%)$ & $13(21 \%)$ \\
Spring 2017 & 105 & $60(57 \%)$ & $39(37 \%)$ & $26(25 \%)$ & $70(67 \%)$ & $14(13 \%)$ & $28(27 \%)$ \\
Fall 2017 & 98 & $64(65 \%)$ & $29(30 \%)$ & $30(31 \%)$ & $63(64 \%)$ & $20(20 \%)$ & $19(19 \%)$ \\
\hline Total & 265 & $160(60 \%)$ & $88(33 \%)$ & $78(29 \%)$ & $180(68 \%)$ & $47(18 \%)$ & $60(23 \%)$ \\
\hline \hline
\end{tabular}

\section{COURSE DESIGN}

Introductory physics courses are generally a compulsory requirement for students seeking to pursue a career in life sciences or medicine. Our course was specifically newly-designed for life sciences majors and hence includes biologically and medically relevant topics [14]. The following list summarizes the main features of the course, for more details see Ref. [13].

$\square$ Active learning and collaboration were promoted during the lectures via several in-class strategies, including weekly 10-minute quizzes, clicker questions, peer discussions, and group quizzes.

$\square$ Metacognition was encouraged by prompting students to reflect on their mistakes via optional exam correction assignments.

- Particular attention was paid to build a learning environment that promotes effort and learning growth. We motivated students to reflect on mindset (fixed versus growth [15]) and we adopted a grading rubric that includes absolute grade lines (i.e. no curving), supports student improvement by dropping students' lowest problem set and in-class quiz scores, and rewards strong performance in the final cumulative exam without unduly raising the stakes of this exam.

$\square$ The course also features a key outside-of-class resource, namely "study-hall", which has emerged as an essential tool for fostering collaboration among students and peer learning, and for bringing faculty and students closer by permitting them to work together in an informal setting.

Study-halls are 2- or 3-hour sessions, offered regularly three times a week outside the lectures, where students can come to ask for help on the course material to instructors and teaching staff (e.g. teaching assistants and undergraduate peer tutors) and work together with their classmates on course assignments. We consider studyhall to be a more inclusive way to hold office-hours: instead of being held in the instructor's office, study-hall takes place in a central location on campus that is convenient for students and in a setting that is conducive to group work and collaboration, for instance with whiteboards and large tables where people can comfortably sit in variable-sized groups. Study-hall is also strategically scheduled, based on students' academic obligations, and when help for course assignments is most needed (for instance, on the night before the homework due-date). Students come to study-hall individually or in groups; they can decide to talk to the instructors or can simply work in groups with their classmates. Because of its regularity in time and location, study-hall facilitates the formation of study-groups. Furthermore, because of its informal and collaborative structure, students also report that they made new friends at study-hall, whom they would have not met otherwise. The presence of the course instructors, instead of only teaching assistants or peer tutors, also contributes significantly to the success of study-hall. By making themselves available outside of class, the instructors communicate the value that they place on the work students do, and that they take personal interest in students' success. Students also come to know and trust their instructors.

\section{COURSE DEMOGRAPHIC AND DATA SET}

Given the life-science focus of our course, it is not surprising that its student audience is composed mostly of pre-medical students (about 80\%) and biological science majors (about 65\%). In Table I we summarize the demographic of the student body for the three consecutive semesters over which we collected the data presented in this paper. The course has a high female population (on average 60\%) and includes significant numbers from groups underrepresented in STEM (on average 30\%). We have defined underrepresented minorities (URM) to include any of the following: Hispanic or Latino of Any Race, Black or African American, American Indian or Alaska Native, Native Hawaiian or other Pacific Islander, Two or more races; and non-URM as: White or Asian [17]. Chi-squared tests confirm that the three semesters analyzed (Table I) are not significantly different, regarding the proportion of URM students, the proportion of female students, or the proportion of female URM students. We have also run a series of one-way ANOVA tests that show that students' mathematics SAT scores, their incoming GPA scores, and their final course grades 
were not significantly different across the three semesters. Therefore, we believe we have enough homogeneity across the three semesters to treat them as a single data set.

\section{DATA COLLECTION}

At the end of each semester, we gathered student feedback through an anonymous online survey, distributed using the Qualtrics survey tool. Participation was voluntary, but students received credit for survey completion, corresponding to $0.5-1 \%$ towards their overall course grade. The response rate each semester was $90 \%$ or higher. The survey consisted of about fifty questions which sought feedback on multiple aspects of the course. Most of the questions were multiple choice, with some open-ended questions for additional comments. Here, we focus on nine of the multiple choice questions, which we believe give a picture of the overall course atmosphere, as perceived by the students, and can speak to whether a supportive community for students has been established. Our hypothesis is that the perceived welcoming atmosphere and collaborative environment is a consequences of the strategies listed above, including study-hall above all. That is why the last question specifically addresses attendance to study-hall.

\section{SURVEY RESULTS}

The nine questions and the corresponding overall responses (from three semesters of the course) are listed next:

○ Q1. How did you find this class overall? Easy (1\%), Average (13\%), Challenging but fair (72\%), Ridiculously difficult (14\%).

- Q2. How would you assess the pace of this course? Incredibly fast (7\%), Fast (61\%), Fine (32\%), Slow $(0 \%)$.

- Q3. How did you find the atmosphere of the course overall? Hostile (1\%), Not welcoming (3\%), Fine $(26 \%)$, Welcoming $(63 \%)$, Love in $(7 \%)$.

- Q4. Did you feel supported and cared about by your classmates? Definitely yes (25\%), Probably yes (44\%), Might or might not (20\%), Probably not (8\%), Definitely not (3\%).

- Q5. Did you feel supported and cared about by your instructors? Definitely yes (49\%), Probably yes $(35 \%)$, Might or might not (10\%), Probably not (5\%), Definitely not (1\%).

- Q6. Have you found it easy to get to know your classmates in this course? (i.e. people you didn't know before) Very easy (23\%), Moderately easy
(61\%), Moderately difficult (13\%), Very difficult $(3 \%)$.

- Q7. How does the class environment that you experienced in this course compare with other STEM classes you have been taking at this university? Much better (44\%), Slightly better (31\%), About the same $(17 \%)$, Slightly worse $(3 \%)$, Much worse $(5 \%)$.

○ Q8. How does the class environment that you experienced in this course compare with other nonSTEM classes you have been taking at this university? Much better (21\%), Slightly better (26\%), About the same (35\%), Slightly worse (11\%), Much worse $(7 \%)$

○ Q9. On average, how many study-hall nights per week have you attended? None (7\%), One-two $(62 \%)$, Two-three $(31 \%)$, All of them (13\%).

For each of the above questions, we have run Fisher's exact test to compare responses between: female and male students, URM and non-URM students, URM female students and non-URM male students. We have found significant difference only for questions 4., 7. and 9. In particular:

- Q4. Did you feel supported and cared about by your classmates? Women responded more positively than men. Fisher's exact test $(95 \% \mathrm{CI}=$ $0.13,0.88 ; \mathrm{p}=0.02, \Phi=0.18)$.

○ Q7. How does the class environment that you experienced in this course compare with other STEM classes you have been taking at this university? URM women responded more positively than nonURM men. Fisher's exact test $(95 \%$ CI $=0.98$, $25.16 ; \mathrm{p}=0.04, \Phi=0.24)$.

○ Q9. On average, how many study-hall nights per week have you attended? URM Women attended study-hall significantly more than non-URM men. Fisher's exact test $(95 \% \mathrm{CI}=0.07,0.59 ; \mathrm{p}=.0009$, $\Phi=0.33)$.

\section{DISCUSSION AND SUMMARY}

Several aspects of the survey results are encouraging. In the first place, it is important to note that this course provides a significant intellectual challenge for these students (Q1, Q2). At the same time, the overall student response to the perceived class atmosphere is positive: the majority of students feel supported and cared by their instructors (Q5) and classmates (Q4); they find the course atmosphere welcoming (Q3); and they find it easy to come to know their classmates (Q6). When asked to 
compare the class environment with other STEM courses (Q7), most students agree that the class climate is better or much better than other STEM classes. Even when comparing the class to non-STEM classes (Q8) the majority of students find the climate of this course is the same or better. It is important to emphasize that the survey results derive from three consecutive semesters of the course, corresponding to different student cohorts and teaching staff. Similar student responses each time adds reliability and suggests that it is indeed our pedagogical strategies that are responsible for the overall positive feedback from students.

Additional information emerges from students' free response to open-ended questions in the survey. In particular, students explicitly express appreciation for the absence of grading on a curve, and the collaborative and caring atmosphere of the class. Here, we collect a few representative comments from these open-ended responses:

"The class really generates a collaborative community through working together in class, on Problem sets, and in study hall. I've enjoyed the process of working with my classmates to solve challenging physics problems and making friends along the way."

"Since everyone is not competing because of a curve, it has been probably the most collaborative classes I've ever taken at (this institution), and everyone just wants to help each other."

"Adding the social aspect to this class has made it a lot more enjoyable and a lot less painful."

"[..] having a professor that cared enough to learn my name and TAs that were able to understand my learning style was unparalleled and I really was able to learn due to it."

These findings are in sharp contrast with the stereotypical negative experience of students in STEM courses [4], and with the results of a recent global assessment of the undergraduate STEM climate at our own institution, which revealed that female students perceive the overall STEM environment more negatively than male students in all aspects examined, and that URM students perceive the classroom environment more negatively than nonURM students [16]. It is especially notable that there is a positive student response, regardless of gender or race: we have found no statistically significant difference in the responses based on gender, URM status, or gender and URM status, except for three instances in which women or URM women reported a more positive experience than men, or non-URM men, respectively. It has been recently observed [11] that women of color tend to have a worse experience in STEM classes than others. However, in our course, URM women find the environment better than other STEM classes at a significantly higher rate than non-URM men, and they attend study-hall significantly more than non-URM men.

Overall, our results suggest that the strategies that we have implemented are inclusive and successful in providing resources that meet at least some of the needs of underrepresented minorities and women. In support of this statement, we report one significant comment that we gathered in the survey through an open-ended question, inviting general comments about STEM climate (which follows questions 7 and 8): A student who identifies as a woman and URM responded: "If this course was the model for sections in CHEM and BIOL classes, I and lots of other students of color would feel more supported in their studies." Going forward, it will be important to test more widely whether these practices have the positive benefits suggested by our experience, i.e. whether they are beneficial beyond the original implementation, beyond our institution, and whether they are applicable beyond physics to other STEM disciplines.

We thank Philip Reeves for help with the data analysis.

[1] CEOSE Biennial Report to Congress, Broadening Participation in America's STEM Workforce (CEOSE 11-01. Arlington, VA, 2009).

[2] National Science Foundation, National Center for Science and Engineering Statistics, Women, Minorities, and Persons with Disabilities in Science and Engineering: 2017 (Special Report NSF 17-310. Arlington, VA, 2017).

[3] National Research Council, Seeking solutions: Maximizing American talent by advancing women of color in academia: Summary of a conference (Washington, DC: National Academies Press, 2013).

[4] E. Seymour and N. M. Hewitt, Talking about leaving: Why undergraduates leave the sciences (Boulder, CO: Westview Press, 1997).

[5] E. Seymour, Science Education 79, 437 (1995).

[6] A.C. Strenta, R. Elliott, R. Adair, M. Matier, J. Scott, Research in Higher Education 35, 513 (1994).

[7] A. C. Johnson, Science Education 91, 805 (2007).

[8] M. Yingyi and L. Yan, Sociology Compass 9, 609 (2015).

[9] H. Garrison and E. L. Dolan, CBE-Life Sciences Education 12, 357 (2013).

[10] R. J. Beichner et al. (edited by E. F. Redish and P. J. Cooney, AAPT, College Park, MD, 2007, Reviews in PER Vol. 1, 2007).

[11] Melissa H. Dancy, et al., PERC Proceedings (2016).

[12] A. J. Cavanagh, CBE-Life Sci Educ 17, ar10 (2018).

[13] C. De Grandi, et al., GIREP Proceedings (To be published) (2017).

[14] S. G. J. Mochrie, Am. J. Phys. 84, 542 (2016).

[15] C. S. Dweck, Mindset: The New Psychology of Success (New York: Random House, 2005).

[16] C. De Grandi, et al., STEM climate survey developed through student-faculty collaboration (Submitted for publication) (2018).

[17] We acknowledge that grouping White and Asian students together neglects important differences in these groups' experiences. We adopt this approach here to focus on the experience of URM students in comparison to others. 